\title{
Vaccination uptake among Australian early childhood education staff: assessing perceptions, behaviours and workplace practices
}

Holly Seale ${ }^{1 *} \mathbb{D}$, Stephanie Dwyer ${ }^{1}$, Alamgir Kabir ${ }^{1}$ and Rajneesh Kaur ${ }^{2}$

\begin{abstract}
Background: Early Childhood Education Centre (ECEC) staff are strongly recommended to receive several immunizations including influenza and pertussis. However, evidence regarding the uptake is either old or lacking across all Australian States/Territories. This study aimed to explore the attitudes and barriers around ECEC staff vaccination and the immunisation policy/practices employed at their workplaces.

Methods: An online cross-sectional survey was undertaken of staff members (administrators and childcare center staff) in early 2017. We compared the individual's knowledge, attitude and practices as well as the centre's policy and practice variables between the vaccinated and unvaccinated respondents. A logistic model was used to identify the factors associated with uptake of the different vaccines.

Results: A total of 575 ECEC staff completed the survey. Sixty percent reported being aware of the recommendations about staff immunisation. While participants did acknowledge that they could spread diseases if unvaccinated (86\%), 30\% could not recall receiving a dTpa in the last 10 years. Private centres were less likely to provide free or onsite vaccination compared to other categories of centres. Less than half reported receiving any encouragement to get the influenza vaccine and only 33\% reported that their centre provides onsite influenza vaccination. Regarding the introduction of mandatory policies, $69 \%$ stated that they would support a policy.

Conclusion: Employers should consider supporting methods to maximize vaccination of their employees including providing free onsite vaccination. Participants were open to idea of mandatory vaccination; however, this needs to be explored further to determine how vaccine costs and access issues could be resolved.
\end{abstract}

Keywords: Immunization, Vaccine, Pediatric, Childcare, Influenza, Pertussis

\section{Background}

The Australian Immunisation Handbook recognises Early Childhood Education Centre (ECEC) staff (i.e. those working in childcare, long day care, preschool) as an occupation at increased risk of some vaccine preventable diseases. People who work with children are 'strongly recommended' to have measles mumps rubella (MMR) vaccine (if non-immune), pertussis (dTpa), varicella (if non-immune) and hepatitis A. Staff members

\footnotetext{
* Correspondence: h.seale@unsw.edu.au

'School of Public Health and Community Medicine, University of New South Wales, Level 2, Samuels Building, Randwick, Sydney, NSW 2031, Australia Full list of author information is available at the end of the article
}

should also 'consider' having the influenza vaccine. Additional vaccinations are recommended for special categories of educators and other staff: hepatitis B for staff who care for children with intellectual disabilities and Japanese encephalitis for those who work in the outer Torres Strait islands for 1 month or more during the wet season. There are currently no mandatory immunisation requirements for Australian ECEC staff members. There is also no supportive funding for vaccines or vaccine administration.

In addition to the Immunisation Handbook, the Australian Government National Health and Medical Research Council published a guideline 'Staying Healthy:

(c) The Author(s). 2019 Open Access This article is distributed under the terms of the Creative Commons Attribution 4.0 International License (http://creativecommons.org/licenses/by/4.0/), which permits unrestricted use, distribution, and reproduction in any medium, provided you give appropriate credit to the original author(s) and the source, provide a link to the Creative Commons license, and indicate if changes were made. The Creative Commons Public Domain Dedication waiver (http://creativecommons.org/publicdomain/zero/1.0/) applies to the data made available in this article, unless otherwise stated. 
preventing infectious diseases in early childhood education and care services [1]. Aside from reinforcing the immunisation recommendations, it also stresses that 'all education and care service staff should be advised of the potential consequences if they refuse reasonable requests for immunisation'. These consequences could include: (1) being restricted to working with children over 12 months old; (2) potentially having to take antibiotics during outbreaks of bacterial diseases that are vaccine preventable; and (3) being excluded from work during outbreaks of vaccine-preventable diseases (even if the educator is not ill). It goes on to recommend that 'employers should develop staff immunisation policy, develop and maintain immunisation records, provide staff with information about vaccine preventable diseases (through in-services training and written material), and take all reasonable steps to encourage non-immune staff to be vaccinated'. Although these guidelines provide for exclusions and encourage vaccination, they are currently not supported by accreditation and licensing requirements.

In 2016, changes were made to the Australian legalisation around the immunisation requirements of children attending kindergarten, long day care, family day care or an occasional care service. Known as the Services Legislation Amendment (No Jab, No Pay/Play) Bill 2015, children need to be fully vaccinated (in accordance with the National Immunisation Program early childhood vaccination schedule, on an approved catch-up schedule or have an approved exemption.) in order to either receive family tax benefits payments and/or in some States/Territories to attend the facility. Vaccine objection (previously known as conscientious objection) is no longer an exemption category. The introduction of the legislation was suggested by some as being coercive because it links the payment of government benefits for childcare to vaccination compliance [2]. Since the introduction of the legislation, the 12 month vaccination coverage has reported to have increased from 92.3 to $93.2 \%$ in 2016 [3].

While there is ongoing attention paid to the immunisation of children, there has been little given to the level of coverage amongst staff members. To the best of our knowledge, the last study undertaken on ECEC staff immunization, policy and practice within the Australian child care setting, took place in 2010 [4]. Since this time, the childcare industry has undergone significant growth and regulatory changes. Three notable changes include: (1) the improved educator to child ratio 1:4 (0-2 years) and 1:5 (2-3 years); (2) the requirement for all staff to attain at least a Certificate III qualification and (3) the introduction of the "no jab no pay or play" immunisation strategy (http:// www.ncirs.edu.au/consumer-resources/no-jab-no-playno-jab-no-pay-policies).
Australian childcare services care for an estimated 1.2 million children under 12 [5], with approximately 17,000 public and private operated, government approved childcare centres catering for children aged 6 weeks to 12 years old [5]. These centres provide formal care through long day care (LDC), family day care (FDC), out of school hours $(\mathrm{OOSH})$, vacation care (VC) and to a lesser extent pre-school [6]. To date there has been very few studies conducted looking at the knowledge, attitudes and practices of ECEC staff towards immunisation [7]. This study examined the immunisation status of ECEC staff members as well as their attitudes towards and barriers against occupational vaccination. It also examined their awareness and perceptions towards their employer's immunisation policies and practices.

\section{Methods}

Approach

A link to an online questionnaire (using SurveyMonkey) was distributed to ECEC staff members via two approaches. Firstly, an information sheet and link to an anonymous electronic survey was distributed to members of the Australian Childcare Alliance (ACA). The ACA is the national peak body that represents childcare providers across Australia (approximately 2500 members). Secondly, the study was advertised via the Early Childhood Australia (national peak body for early childhood) newsletter and their social media pages (membership numbers unknown). The survey was available online in early 2017. Members of these peak national bodies include those working in a range of ECEC settings: preschool, long day care, family day care, occasional care, mobile services and specialist programs.

The study was approved by the University of New South Wales Human Research Ethics Panel. Consent was implied if the participants completed and submitted the survey,

\section{Instrument}

Questionnaire items were developed using instruments from previous studies examining knowledge, attitudes and practices [8-10]. Additional items were developed which were deemed relevant to the current Australian immunisation situation. The questionnaire contained 59 items plus demographic questions. The questionnaire assessed: (1) attitudes towards awareness of recommendations; (2) perceptions towards risk from infection and staff vaccination; (3) perceived facilitators and barriers to staff vaccination, (4) immunisation status related to pertussis, hepatitis A and B, tetanus and seasonal influenza vaccine; (5) current childcare services policy and practices on staff immunisation; and (6) demographics. The names of the individual diseases were used, rather than the commercial names of the vaccines or the 
combination vaccines (i.e. dTpa). This may have affected the accuracy of the reporting. In addition, the questionnaire assessed attitudes regarding a proposed staff mandatory vaccination policy. A staff mandatory vaccination policy was defined as a policy requiring all staff except those with a medical contraindication to receive all recommended vaccines to remain employed. Knowledge and attitudes questions were examined by extent of agreement with statements about each vaccine, using a five-point Likert scale (i.e., disagree strongly, disagree somewhat, somewhat agree, and strongly agree, neither agree nor disagree) (Additional file 1).

\section{Data analysis}

Survey responses using a likert scale were categorized as "expressed agreement" if respondents marked "strongly agree" or "somewhat agree" and as "expressed disagreement" if respondents marked "strongly disagree" or "somewhat disagree" or "neither agree or disagree". All the categorical variables were summarised as number (\%). Characteristics of the childcare centre and their employees were compared between those who reported receipt of each vaccine and those who denied receipt of the respective vaccine using chisquare, or fisher exact and Wilcoxon Signed ranks test wherever appropriate. Vaccine coverage for each vaccine was compared to coverage of influenza vaccines in years 2015 and 2016 using McNemar test for paired data. We compared the responses for the knowledge, attitude and practice questions as well as the questions relating to the centre's policy and practices between the vaccinated and unvaccinated respondents using Pearson's Chi Square test. We used a multiple logistic model to identify the factors associated with uptake of different vaccines. We put all the variables that were significantly associated with the specific vaccine uptake based on the bivariate analysis at $p<0.20$ into the multiple logistic model. However, the variables focused on the centre's policy and practices had to be removed despite their significant association in the model as they were too many missing values. A backward elimination approached was used based on Akaike Information Criterion to keep the important variables in the final model. We also compared the responses of staff working in privately operated centres with those from other types of centres. All tests were two-tailed, and statistical significance was set at $P<0.05$. All the analyses were conducted using R3.4.2.

\section{Results}

A total of 576 surveys were commenced and 575 completed. Of the participants, the majority were female (99\%), aged 30 years or older (86\%) and spoke only English (87\%). Around 50\% had been in the ECEC workforce for 16 years or more $(47 \%)$, with a similar number reporting that they worked in a privately-operated centre $(50.4 \%)$ (Table 1). The survey respondents were representative of the workforce in age and gender, however our survey participants had been in the ECEC workforce longer than average number of years reported in the 2016 ECEC National Workforce Census [11]. Just under half (47.1, 95\% CI: 43.0, 51.3) reported receiving an influenza vaccine in 2016. While tetanus uptake was close to $91 \%$ (95\% CI: 89,93$)$, uptake for the other vaccines was lower with ranges between 48 and $76 \%$ (Table 2). There was no significant difference in the rates of influenza vaccine in 2016 compared to 2015 $(P=0.539)$. The number receiving the hepatitis vaccine was much larger $(364 / 482,75.5 \%)$ compared to those getting influenza vaccine $(256 / 543,47.1 \%)$ in 2016 . This difference was of high statistical significance $(P<0.001)$. Similarly, the rates of hepatitis $B$ vaccine were significantly $(P<0.001)$ higher than those receiving the influenza vaccine $(260 / 542,48 \%)$ in 2015 . Hepatitis B was significantly $(p<0.001)$ received by a lower number (364/482, 75.5\%) of individuals than those receiving tetanus vaccine, which was received by $(483 / 529,91.3 \%)$ participants (Table 2).

The responses to the attitudinal questions focused on workplace vaccination policy and practices are presented in Table 3. Not all participants were aware of immunization recommendations outlined in the Australian Immunisation Handbook (67\%), though pertussis vaccine recipients were more likely to be aware than the unvaccinated ( $71 \%$ vs $54 \%$, $p=0.001$ ). A slightly higher proportion reported being aware of the National Health and Medical Research Council (NHMRC) guidelines, with individuals reporting pertussis vaccination again being more likely to be aware than the unvaccinated individuals ( $78 \%$ vs $62 \%, p<0.001)$. Eightyfour percent agreed that ECEC staff should be offered vaccination free of charge, with a significantly higher proportion of the vaccinated individuals agreeing with this statement compared to the unvaccinated individuals $(88 \%$ vs $70 \%, p<0.001$ ).

Regarding the introduction of mandatory policies, $69.4 \%$ stated that they would support a policy, with moderate increases in support if the vaccine was offered onsite $(70.6 \%)$ or offered free of charge (75.5\%). Only $43 \%$ reported that they were aware of a centre specific policy around vaccination, while $60 \%$ nominated that their centre keeps records of their vaccination status (Table 3). Of concern was the fact that only $51 \%$ reported that their centre encourages them to get vaccinated. Only one-fourth of participants nominated that their centre provided onsite influenza vaccination, with even lower numbers reporting access to free vaccination. Participants were more likely to be fully vaccinated from centres which: have a policy around staff's vaccination, keep records of their vaccination status, encourage staff to get vaccinated and ask about updates in staff 
Table 1 Descriptive statistics of the study sample

\begin{tabular}{|c|c|c|c|c|}
\hline \multirow[t]{2}{*}{ Characteristics } & \multicolumn{2}{|l|}{ Influenza } & \multicolumn{2}{|l|}{ Pertussis } \\
\hline & $\begin{array}{l}\text { Vaccinated } \\
\mathrm{n}(\%)\end{array}$ & $\begin{array}{l}\text { Unvaccinated } \\
\mathrm{n}(\%)\end{array}$ & $\begin{array}{l}\text { Vaccinated } \\
\mathrm{n}(\%)\end{array}$ & $\begin{array}{l}\text { Unvaccinated } \\
\mathrm{n}(\%)\end{array}$ \\
\hline Sex & $n=539$ & & $n=527$ & \\
\hline Female & $250(46.4)$ & $281(52.1)$ & $394(75.9)$ & $125(24.1)$ \\
\hline Male & $4(50)$ & $4(1.4)$ & $3(37.5)$ & $5(62.5)$ \\
\hline$p$-value & & $0.573^{*}$ & & $0.025^{*}$ \\
\hline Age (years) & $n=543$ & & $n=531$ & \\
\hline$<30$ & $31(44.9)$ & $40(57.9)$ & $58(89.2)$ & $7(10.8)$ \\
\hline $30-39$ & $61(38.9)$ & $96(61.1)$ & $125(79.1)$ & $33(20.9)$ \\
\hline $40-49$ & $61(40.7)$ & $89(59.3)$ & $107(71.8)$ & $42(28.2)$ \\
\hline $50-59$ & $71(60.7)$ & $46(39.3)$ & $73(65.8)$ & $38(34.2)$ \\
\hline$\geq 60$ & $32(68.1)$ & 15 (31.9) & $36(76.6)$ & $11(23.4)$ \\
\hline$p$-value & & 0.001 & & 0.020 \\
\hline \multicolumn{5}{|l|}{ Country of origin } \\
\hline Australia & $215(49.8)$ & $217(50.2)$ & $332(78.7)$ & $90(21.3)$ \\
\hline England & $12(42.9)$ & $16(57.1)$ & $20(74.1)$ & $7(25.9)$ \\
\hline New Zealand & $9(52.9)$ & $8(47.1)$ & $13(81.3)$ & $3(18.7)$ \\
\hline Other & $20(30.3)$ & $46(69.7)$ & $35(53.0)$ & $31(47.0)$ \\
\hline$p$-value & & 0.225 & & $<0.001$ \\
\hline \multicolumn{5}{|l|}{ Language spoken } \\
\hline English only & $226(49.3)$ & $232(50.7)$ & $353(79.1)$ & $93(20.9)$ \\
\hline Bilingual & $22(33.8)$ & $43(66.2)$ & $36(54.5)$ & $30(45.5)$ \\
\hline$p$-value & & 0.184 & & $<0.001$ \\
\hline \multicolumn{5}{|l|}{ Education level } \\
\hline High school or less & $5(38.5)$ & $8(61.5)$ & $8(38.5)$ & $5(61.5)$ \\
\hline Under graduate & $127(52.0)$ & $117(48.0)$ & $180(76.3)$ & $56(23.7)$ \\
\hline Postgraduate & $28(39.5)$ & $43(60.5)$ & $51(70.8)$ & $21(29.2)$ \\
\hline Certificate/ Diploma & $96(44.7)$ & $119(55.3)$ & $161(76.6)$ & $49(23.4)$ \\
\hline$p$-value & & 0.280 & & 0.365 \\
\hline \multicolumn{5}{|l|}{ State } \\
\hline New South Wales & $81(44.3)$ & $102(55.7)$ & $147(80.8)$ & $35(19.2)$ \\
\hline Queensland & $61(50)$ & $61(50)$ & $105(83.3)$ & $21(16.7)$ \\
\hline Victoria & $59(44.7)$ & $73(55.3)$ & $82(65.1)$ & $44(34.9)$ \\
\hline South Australia & $30(73.2)$ & $11(27.8)$ & $26(72.2)$ & $10(27.8)$ \\
\hline Western Australia & $11(34.4)$ & $21(65.6)$ & $16(55.2)$ & $13(44.8)$ \\
\hline Other & $14(43.8)$ & $18(56.2)$ & $24(77.4)$ & $7(22.6)$ \\
\hline$p$-value & & 0.031 & & 0.004 \\
\hline \multicolumn{5}{|l|}{ Employment status } \\
\hline Full time & $156(46.7)$ & $178(53.3)$ & $250(62.8)$ & $80(62.5)$ \\
\hline Part time & $77(50)$ & $77(50)$ & $116(29.1)$ & $36(28.1)$ \\
\hline Casual & $17(40.5)$ & $25(59.5)$ & $26(6.5)$ & $10(7.8)$ \\
\hline Student & $4(50)$ & $4(50)$ & $6(1.5)$ & $2(1.6)$ \\
\hline$p$-value & & 0.844 & & 0.545 \\
\hline
\end{tabular}


Table 1 Descriptive statistics of the study sample (Continued)

\begin{tabular}{|c|c|c|c|c|}
\hline \multirow[t]{2}{*}{ Characteristics } & \multicolumn{2}{|l|}{ Influenza } & \multicolumn{2}{|l|}{ Pertussis } \\
\hline & $\begin{array}{l}\text { Vaccinated } \\
\text { n (\%) }\end{array}$ & $\begin{array}{l}\text { Unvaccinated } \\
\mathrm{n}(\%)\end{array}$ & $\begin{array}{l}\text { Vaccinated } \\
\text { n (\%) }\end{array}$ & $\begin{array}{l}\text { Unvaccinated } \\
\mathrm{n}(\%)\end{array}$ \\
\hline \multicolumn{5}{|l|}{ Child care experience } \\
\hline$<1$ year & $6(30.0)$ & $14(70.0)$ & $12(70.6)$ & $5(29.4)$ \\
\hline $1-3$ years & $16(50)$ & $16(50)$ & $23(82.1)$ & $5(17.9)$ \\
\hline $4-6$ years & $27(49.0)$ & $28(51.0)$ & $40(72.7)$ & $15(27.3)$ \\
\hline $7-10$ years & $31(34.1)$ & $60(65.9)$ & $66(75.9)$ & $21(24.1)$ \\
\hline $11-15$ years & $44(50.6)$ & $43(49.4)$ & $69(80.2)$ & $17(19.8)$ \\
\hline$\geq 16$ years & $130(60.0)$ & $125(40.0)$ & $189(74.1)$ & $66(25.9)$ \\
\hline$p$-value & & 0.130 & & 0.877 \\
\hline \multicolumn{5}{|l|}{ Type of day care } \\
\hline Family day care & $17(53.1)$ & $15(46.9)$ & $25(83.3)$ & $5(16.7)$ \\
\hline Long day care- community-run & $75(50.7)$ & $73(49.3)$ & $106(71.1)$ & $43(28.9)$ \\
\hline Long day care- privately owned & $122(45.0)$ & $149(55.0)$ & $211(79.6)$ & $54(20.4)$ \\
\hline Other & $40(47.6)$ & $44(52.4)$ & $54(68.4)$ & $25(31.6)$ \\
\hline$p$-value & & 0.763 & & 0.090 \\
\hline \multicolumn{5}{|l|}{ Centre ownership } \\
\hline Private & $110(45.8)$ & $130(54.2)$ & $191(82.3)$ & $44(18.7)$ \\
\hline Local council & $26(63.4)$ & 15 (36.6) & $28(71.8)$ & $11(28.2)$ \\
\hline Community & $31(47.7)$ & $34(52.3)$ & $43(68.3)$ & $20(31.7)$ \\
\hline Employer (University or Company & $14(46.7)$ & $16(53.3)$ & $24(80.0)$ & $6(20.0)$ \\
\hline Non-profit organisation & $56(44.1)$ & $71(55.9)$ & $86(68.8)$ & $39(31.2)$ \\
\hline Other & $15(46.9)$ & $17(53.1)$ & $22(71.0)$ & $9(29)$ \\
\hline$p$-value & & 0.321 & & 0.029 \\
\hline \multicolumn{5}{|l|}{ No of children enrolled } \\
\hline$\leq 20$ & $15(50.0)$ & $15(50.0)$ & $18(64.3)$ & $10(35.7)$ \\
\hline $21-50$ & $54(46.2)$ & $63(53.8)$ & $83(70.3)$ & $35(29.7)$ \\
\hline $51-100$ & $105(46.3)$ & $122(53.7)$ & $169(77.2)$ & $50(22.8)$ \\
\hline$>100$ & $80(49.7)$ & $81(50.3)$ & $126(79.7)$ & $32(20.3)$ \\
\hline$p$-value & & 0.720 & & 0.096 \\
\hline
\end{tabular}

${ }^{*} P$ values are derived from Fisher Exact test, for the rest of the variables Wilcoxon Sign rank test was used

vaccination status. The factors associated with uptake of influenza vaccination: believing that the vaccine protect against illness (Adj. OR: 4.15, 95\% CI: $1.44,12.88)$, agreeing with the importance of receiving the vaccine each year (Adj. OR: 9.24, 95\% CI: $4.16,21.31$ ) and being happy to pay for it (Adj. OR: 3.13, 95\% CI: 1.41, 6.78). Whereas factors associated with hepatitis A vaccine uptake included: agreeing in the importance of the vaccine (Adj. OR: 5.11, 95\% CI: $2.04,13.33)$, being aged $>30$ years, and working in a centre with between 50 and 100 children (Adj. OR: 4.12, 95\% CI:1.20, 13.86) (Table 4).

Table 5 presents the differences in knowledge and attitudes amongst participants working in privately owned centres versus other types of centres.
Participants from private centres were more likely to be familiar with the immunisation recommendations. One-fourth of participants from privately-owned centres reported that their centre provides flu vaccine free of cost while about half of the staffs from centres owned by others reported the same $(p<0.001)$. About $20 \%$ of participants from the privately-owned centres reported that their centre provides onsite flu vaccine while $30 \%$ of participants from other types of centres reported onsite access $(p=0.013)$.

\section{Discussion}

Overall, we found mixed levels of awareness regarding the recommendations for vaccination of ECEC staff. Participants reported that not all centres have individual 
Table 2 Vaccine coverage among the study participants

\begin{tabular}{|c|c|c|c|c|c|}
\hline Vaccines & $\begin{array}{l}\text { Total number of } \\
\text { respondents }\end{array}$ & $\begin{array}{l}\text { Number of vaccinated } \\
\text { individuals }\end{array}$ & $\begin{array}{l}\text { Vaccine } \\
\text { coverage }^{a}\end{array}$ & Comparison of vaccine coverage & $\begin{array}{l}P \\
\text { value }\end{array}$ \\
\hline Influenza (in 2016) & 543 & 256 & 47.1 & \multirow{2}{*}{$\begin{array}{l}\text { Influenza (in 2016) with Influenza (in } \\
\text { 2015) }\end{array}$} & \multirow[t]{2}{*}{0.539} \\
\hline Influenza (in 2015) & 542 & 260 & 48.0 & & \\
\hline \multirow[t]{2}{*}{ Hepatitis A series ${ }^{b}$} & 497 & 365 & 73.4 & Hepatitis A with Influenza (in 2016) & $\begin{array}{l}< \\
0.001\end{array}$ \\
\hline & & & & Hepatitis A with Influenza (in 2015) & $\begin{array}{l}< \\
0.001\end{array}$ \\
\hline \multirow[t]{2}{*}{$\begin{array}{l}\text { Pertussis (Whooping } \\
\text { Cough) }\end{array}$} & 531 & 400 & 75.3 & Pertussis with Influenza (in 2015) & $\begin{array}{l}< \\
0.001\end{array}$ \\
\hline & & & & Pertussis with Influenza (in 2015) & $\begin{array}{l}< \\
0.001\end{array}$ \\
\hline \multirow[t]{2}{*}{ Hepatitis B series $^{d}$} & 482 & 364 & 75.5 & Hepatitis B with Influenza (in 2015) & $\begin{array}{l}< \\
0.001\end{array}$ \\
\hline & & & & Hepatitis with Influenza (in 2015) & $\begin{array}{l}< \\
0.001\end{array}$ \\
\hline \multirow[t]{3}{*}{ Tetanus ${ }^{\mathrm{e}}$} & 529 & 483 & 91.3 & Hepatitis B and tetanus & $\begin{array}{l}< \\
0.001\end{array}$ \\
\hline & & & & Tetanus with Influenza (in 2016) & $\begin{array}{l}< \\
0.001\end{array}$ \\
\hline & & & & Tetanus with Influenza (in 2016) & $\begin{array}{l}< \\
0.001\end{array}$ \\
\hline
\end{tabular}

${ }^{a}$ Coverage has been calculated as $(\mathrm{n} / \mathrm{N}) * 100$

${ }^{\mathrm{b}}$ Two shots ever

In the last 10 years

d Three shots ever

eUsually provided in combination with diphtheria and pertussis

policies regarding staff vaccination, nor do they track uptake. Of concern, was the finding that not all centres are advocating for staff vaccination and very few are providing onsite access. It is perhaps not surprising that we found mixed results when it came to actual vaccine uptake, especially for influenza. Apart from the data presented in this study, there have been few previous attempts to document vaccine uptake in the childcare sector. One study conducted by Spokes et.al over 10 years ago, involved a survey of New South Wales based childcare directors $(n=437)$ to determine their level of knowledge towards the NHMRC recommendations for the immunisation of child-care workers and to ascertain whether the knowledge had translated into practices [12]. The study found that only $49 \%$ of the respondents were aware of the policy and just over half had a staff immunisation policy in place. Fast forward to 2017 and while there have been marginal increases in knowledge levels, there has been little in the way of improvements in meeting the NHMRC recommendations. In support of our findings, Spokes et.al also identified that centres that were operating for profit were significantly less likely to offer to pay all or part of the cost of immunisation of staff. Centres that were aware of the NHMRC recommendations and identified as part of a larger organisation were significantly more likely to offer to pay the whole or part of the cost of immunisation. However, this did not remain significant in the multivariate logistic regression [12].

Interestingly, overwhelmingly participants acknowledged that influenza can spread from children to staff member but only $40 \%$ agreed that their level of risk was heightened. Encouragingly 60\% acknowledge that they felt they had an obligation to be vaccinated against the flu to reduce the risk to the children in their care. However, obligation or willingness to get vaccinated does not always translate to actual receipt with only $50 \%$ of participants reported receiving a flu vaccine in 2016. Most of our knowledge about occupational influenza vaccination comes from examining uptake amongst hospital healthcare workers and aged care staff. In those settings, multi-factorial components, such as attitudes, motivation, perceived threat, beliefs, self-efficacy, and sociocultural influences have all been found to impact on uptake [13].

Inconvenience and cost of vaccination may be having an impact on uptake amongst ECEC staff. There was a positive response to the suggestion of free vaccination amongst participants. To date there has been little work done to examine the impact of free on-site influenza vaccination on childcare staff vaccination prevalence. A small study conducted in one childcare centre over four influenza seasons found that the introduction of free influenza vaccination improved uptake (28 to 51\%) [14]. In 
Table 3 Comparison of attitudes across child care workers by vaccination status

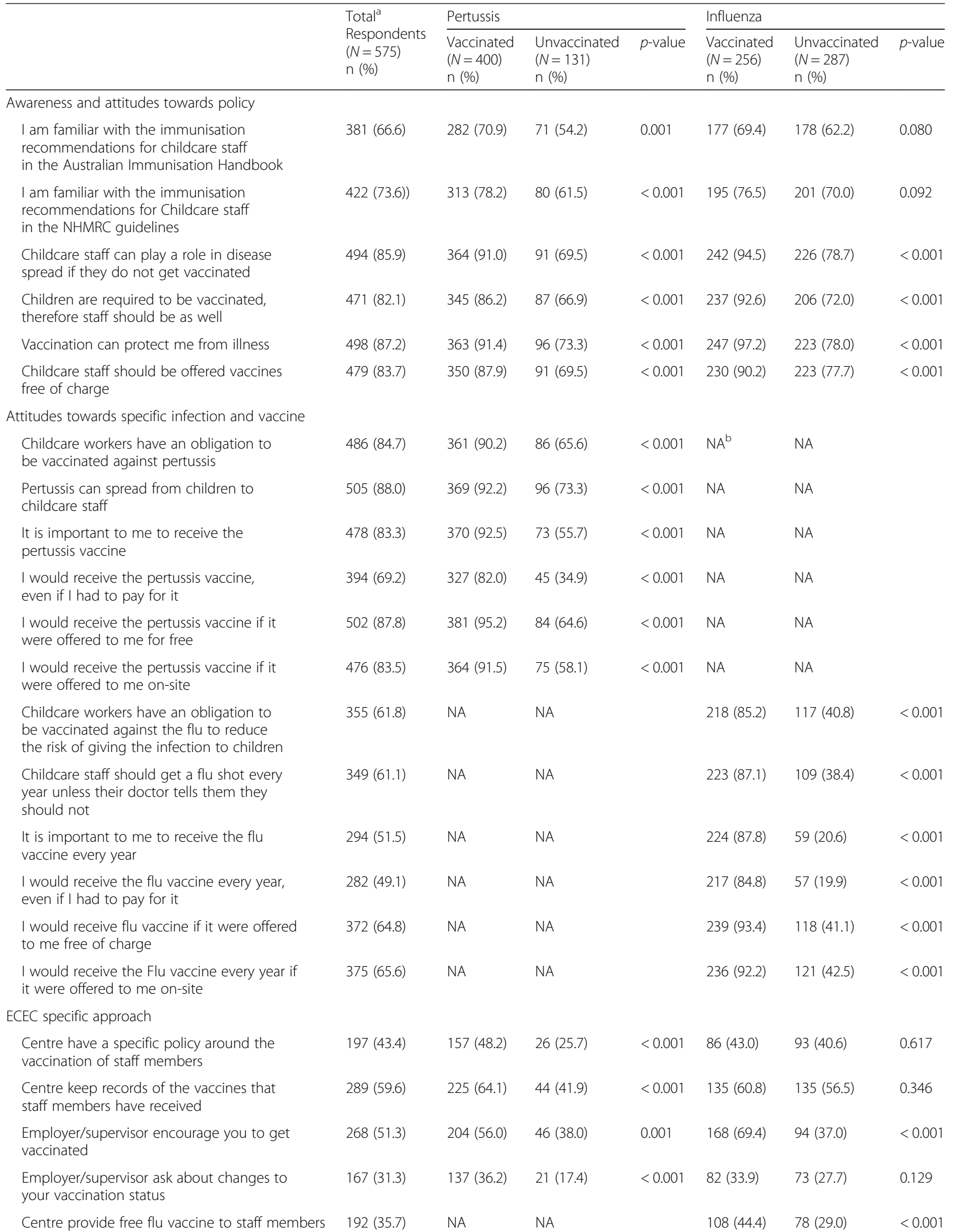


Table 3 Comparison of attitudes across child care workers by vaccination status (Continued)

\begin{tabular}{|c|c|c|c|c|c|c|c|}
\hline & \multirow{2}{*}{$\begin{array}{l}\text { Total }^{\mathrm{a}} \\
\text { Respondents } \\
(N=575) \\
n(\%)\end{array}$} & \multicolumn{3}{|l|}{ Pertussis } & \multicolumn{3}{|l|}{ Influenza } \\
\hline & & $\begin{array}{l}\text { Vaccinated } \\
(N=400) \\
n(\%)\end{array}$ & $\begin{array}{l}\text { Unvaccinated } \\
(N=131) \\
n(\%)\end{array}$ & $\overline{p \text {-value }}$ & $\begin{array}{l}\text { Vaccinated } \\
(N=256) \\
n(\%)\end{array}$ & $\begin{array}{l}\text { Unvaccinated } \\
(N=287) \\
n(\%)\end{array}$ & $\overline{p \text {-value }}$ \\
\hline Centre provide onsite flu vaccination & $140(25.5)$ & NA & NA & & $88(34.4)$ & $51(17.8)$ & $<0.001$ \\
\hline
\end{tabular}

${ }^{a}$ Denominator varies due to missing value

${ }^{\mathrm{b}} \mathrm{NA}$, variable not applicable for a specific vaccine

the healthcare setting, facilities often adopt a range of program strategies to try and improve influenza vaccination uptake amongst healthcare workers. Most sites have attempted to remove these administrative barriers by providing on-site free vaccination services at convenient times that are easily accessible by healthcare workers (HCWs) [15-17]. However, removal of these barriers alone may not necessarily lead to coverage rates above $70 \%$. It has also been suggested in the healthcare setting that too much emphasis has been placed on initiatives like reminders, education, incentives, promotion in the workplace, and easy access to free vaccination, especially considering the small increases in $\mathrm{HCW}$ vaccination gained. It has been postulated that more energy needs to be placed on developing interventions which incorporate behavioural psychology and health behaviour change theories [13]. While these recommendations are squarely targeted at healthcare facilities, it could be reasoned that there is value in considering them when developing any interventions aimed at improving uptake in the early childhood education sector.

As previously mentioned, a booster dose of dTpa is recommended for childcare staff if 10 years has elapsed since a previous dose. Given the increased number of pertussis outbreaks documented recently in the United States and elsewhere [18], the finding that one third of participants had not received a booster in the last 10 years is concerning. While there is no evidence to link spread from childcare staff to the children in their care, there has been recent studies suggesting that cases of pertussis are not always linked to household contacts.

For example, a UK study which examined the sources of infection among household contacts of infants under 3 months of age with laboratory-confirmed pertussis, found no identifiable source of infection for half of the cases [19]. The authors proposed that the role of external contacts as source of transmission is often overlooked. Based on data from four countries, they concluded that, in the absence of an identifiable source within the household, around 1 in 3 babies hospitalized were infected by a contact outside the household. Perhaps not surprising that the risk of infection from these sources was suggested to depend on the frequency and intensity of contact [20]. Linking back to the childcare setting, infants (especially those not yet mobile) have frequent and often prolonged close contact with childcare staff members, while they are being comforted, fed and changed. The study authors suggested that beyond routine vaccination of pregnant women, a cocooning strategy (vaccination of contacts of newborns to produce a circle of protection around infants against the disease) that includes other household contacts like fathers, siblings and grandparents should be encouraged [19]. However, there are other important contacts outside that proposed group include healthcare workers, early childhood health nurses, and childcare staff that should be considered.

While the idea of mandatory vaccination for childcare staff is not currently being debated, we felt it was useful to measure the current climate amongst participants towards the idea. We were surprised to see that a large proportion of participants would support mandatory vaccination in the sector. We are not the only ones to document this high level of support. Rebman et.al. also found that most of the parents and staff they surveyed supported a mandatory staff vaccination policy or agency certification program, with no differences in responses between parents versus staff [8]. In support of our findings, Rebman also found that both staff and administrators are more likely to support a mandatory policy if vaccines are offered onsite and free of charge. Only $10 \%$ of staff said they would quit if vaccines other than the already-required hepatitis A were mandatory. Further work needs to be undertaken to explore the climate around mandatory vaccination including the support from Australian parents and administrators and the strategies that could be used to govern the introduction.

A major strength of this study is that it is the first to assess nationally current immunisation practices, as well as the level of support for mandatory vaccination policy which could be used in the future to drive strategy change. It is also the first to report the attitudes of childcare staff following the introduction of the new 'no jab no pay/play' legalisation. Limitations of this study include the probability of social desirability and selection biases because individuals most interested in staff vaccination were likely to respond. While we received responses from childcare staff across all states/territories, some regional centres may not be appropriately represented. We relied on self-reported vaccine uptake and 
Table 4 Factors associated with vaccination against influenza and pertussis

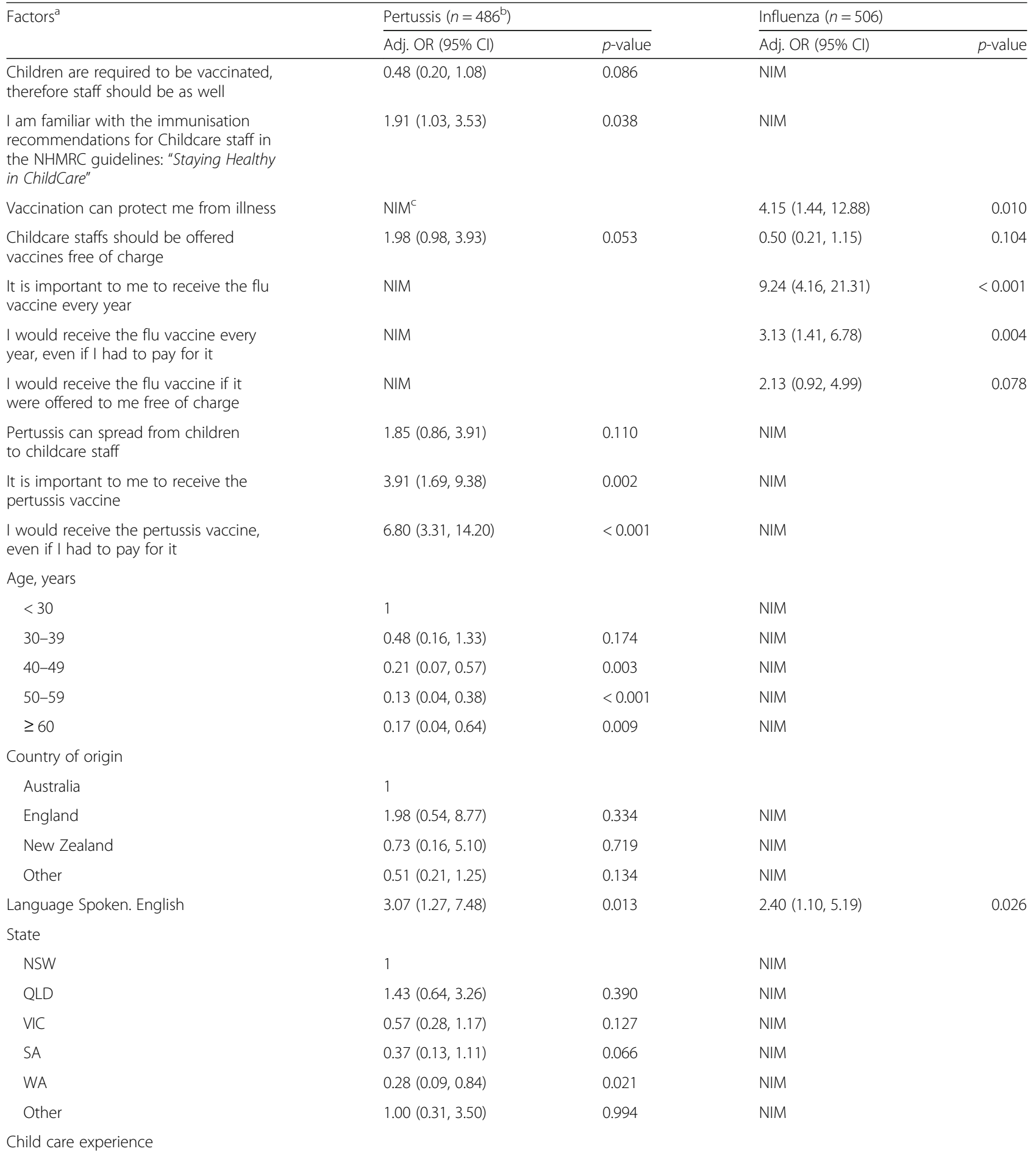

${ }^{a}$ We did not include the variables on centre's policy and practice irrespective of their significant association in the bivariate analysis due to missing variables ${ }^{b}$ No of observations used in the multiple logistic model

${ }^{\mathrm{C}} \mathrm{NIM}$, Not included in the model

did not collect data on the uptake of combination vaccines, rather we asked whether participants had received a vaccine against either 'tetanus' or 'pertussis'. This may have led to confusion and potential underestimation of vaccine uptake. Currently, we have no understanding of strategies used within ECEC settings around the documentation, promotion and whether there is any follow up regarding the vaccination of childcare staff. Further 
Table 5 Attitudes towards immunisation policy and practices by participants from privately-owned versus those from other centres

\begin{tabular}{|c|c|c|c|c|}
\hline & $\begin{array}{l}\text { Total } \\
(N=575) \\
\mathrm{n}(\%) \\
\end{array}$ & $\begin{array}{l}\text { Privately owned } \\
(\mathrm{N}=256) \\
\mathrm{n}(\%)\end{array}$ & $\begin{array}{l}\text { Community, council/other } \\
(N=310) \\
n(\%)\end{array}$ & $p$-value \\
\hline $\begin{array}{l}\text { I am familiar with the immunisation recommendations } \\
\text { for Childcare staff in the Australian Immunisation Handbook }\end{array}$ & $376(66.5)$ & $188(73.4)$ & $188(60.8)$ & 0.002 \\
\hline $\begin{array}{l}\text { I am familiar with the immunisation recommendations for } \\
\text { Childcare staff in the NHMRC guidelines: "Staying Healthy } \\
\text { in Childcare" }\end{array}$ & $418(73.9)$ & $208(81.2)$ & $210(67.7)$ & $<0.001$ \\
\hline The centre provides free flu vaccine to staff members & $186(35.1)$ & $59(24.4)$ & $127(44.1)$ & $<0.001$ \\
\hline The centre provides onsite flu vaccine & $136(25.1)$ & $49(19.8)$ & $87(29.5)$ & 0.013 \\
\hline The centre encourages the staff to get vaccinated? & $262(50.9)$ & $119(51.3)$ & $143(50.5)$ & 0.933 \\
\hline The centre asks about changes to staff member's vaccination status & $166(31.6)$ & $97(41.5)$ & $69(23.6)$ & $<0.001$ \\
\hline
\end{tabular}

work will need to be undertaken to examine whether any activities occur regarding the promotion and/or delivery of immunisation within centres. Lastly, we were unable to accurately calculate a response rate due to the strategies that were used to advertise the study via mailing lists/newsletters.

\section{Conclusion}

ECEC workers may be exposing themselves, the children they care for, colleagues, parents and community members to vaccine preventable diseases because they may not have received the recommended vaccines. This study of immunisation policy and practices in childcare identified deficiencies in awareness towards recommendations, variations in practice around vaccine provision and record keeping and gaps in immunisation uptake. If centres are going to achieve higher coverage rates, then they must reduce the barriers to vaccination, namely through providing free onsite vaccination. Participants were open to idea of mandatory vaccination; however, this needs to be explored further to determine how vaccine costs and access issues could be resolved.

\section{Additional file}

Additional file 1: Survey tool. (DOCX $34 \mathrm{~kb})$

\section{Abbreviations}

ACA: Australian Childcare Alliance; ECEC: Early Childhood Education Centre; FDC: Family day care; HCW: Healthcare workers; LDC: Long day care; NHMRC: National Health and Medical Research Council; OOSH: Out of school hours; VC: Vacation care

\section{Acknowledgments}

We would like to thank the Australian Childcare Alliance and Early Childhood Australia for distributing the information about the study. Additional thanks go to those ECEC staff who completed the survey.

\section{Authors' contributions}

HS conceived and designed this study and was responsible for data collection/analysis and development of the manuscript, with all authors contributed to updates to the final manuscript. SD contributed to a literature review to support the study and contributed to the survey development. AK and RK contributed to the statistical analysis and write up of the results. All authors have read and approved the manuscript.

\section{Funding}

Not applicable

Availability of data and materials

De-identified data is available upon request from the corresponding author.

\section{Ethics approval and consent to participate}

The study was approved by the University of New South Wales Human Research Ethics Panel (HC17011). Information was provided about the study to potential participants and consent was implied if the participants completed and submitted the survey.

\section{Consent for publication}

Not applicable

\section{Competing interests}

Dr. Holly Seale has previously received funding from drug companies for investigator driven research and consulting fees to present at conferences/ workshops and develop resources (bio-CSL/Sequiris, GSK and Sanofi Pasteur). She has also participated in advisory board meeting for Sanofi Pasteur. Dr. Seale is an editorial board member for BMC Infectious Diseases. The other authors do not have anything to declare.

\section{Author details}

${ }^{1}$ School of Public Health and Community Medicine, University of New South Wales, Level 2, Samuels Building, Randwick, Sydney, NSW 2031, Australia. ${ }^{2}$ Psychosocial Research Group, Prince of Wales Clinical School, University of New South Wales, Sydney, Australia.

Received: 9 October 2018 Accepted: 29 August 2019

Published online: 14 September 2019

\section{References}

1. Australian Government National Health and Medical Research Council. Staying healthy: preventing infectious diseases in earlychildhood education and care services. 5th ed. Canberra; 2013. https://www.nhmrc.gov.au/aboutus/publications/staying-healthy-preventing-infectious-diseases-earlychildhood-education-and-care-services.

2. Australian Government. Social services legislation amendment (no jab, no pay) act 2015. In: Services S, editor. Senate community affairs legislation committee. Canberra: Commonwealth of Australia; 2015. ACT 158.

3. Porter C. No jab, no pay lifts immunisation rates. Canberra: Commonwealth of Australia; 2016.

4. Hope K, Butler M, Massey P, Cashman P, Durrheim DN, Stephenson J, Worley A. Pertussis vaccination in child care workers: room for improvement in coverage, policy and practice. BMC Pediatr. 2012;12:98.

5. The Social Research Centre. The national early childhood education and care (ECEC) workforce census 2013. Melbourne: PricewaterhouseCoopers Australia; 2014. 
6. Australian Government. Employment outlook to November 2019. Canberra: Labour Market Research and Analysis Branch; 2015.

7. Australian Government. The Australian immunisation handbook, vol. Publications approval number: 11162. 10th ed. Canberra: Australian Governmnet Department of Health; 2015.

8. Rebmann T, Wang J, Wilson KD, Gilbertson PG, Wakefield M. Parents' and staff's support for a childcare agency employee mandatory vaccination policy or agency certification program. Am J Infect Control. 2016:44:799-804.

9. Tuckerman J, Thomas N, Marshall HS. Should professionals caring for children be vaccinated? Community perspectives on health care and child care worker immunisation. Vaccine. 2016;34(14):1726-32.

10. Rebmann T, Arnold LD, Elliott MB, Gilbertson PG, Wakefield M. Vaccination for child clients and employees in St Louis childcare agencies: vaccine uptake and policies versus parents' perceptions. Am J Infect Control. 2016; 44(9):1010-5.

11. Social Research Centre. 2016 early childhood education and care national workforce census. Melbourne; 2017. https://docs.education.gov.au/system/ files/doc/other/2016_ecec_nwc_national_report_sep_2017_0.pdf.

12. Spokes PJ, Ferson MJ, Ressler KA. Staff immunisation: policy and practice in child care. J Paediatr Child Health. 2011;47:530-4.

13. Corace K, Garber $G$. When knowledge is not enough: changing behavior to change vaccination results. Hum Vaccin Immunother. 2014;10:2623-4.

14. Lee I, Thompson S, Lautenbach E, Gasink LB, Watson B, Fishman NO, Chen Z, Linkin DR. Effect of accessibility of influenza vaccination on the rate of childcare staff vaccination. Infect Control Hosp Epidemiol. 2008:29:465-7.

15. Black CL, Yue X, Ball SW, Donahue SMA, Izrael D, de Perio MA, Scott Laney A, Williams WW, Lindley MC, Graitcer SB, et al. Influenza vaccination coverage among health care personnel — United States, 2014-15 influenza season. MMWR. 2015;64:993-9.

16. Sartor C, Tissot-Dupont H, Zandotti C, Martin F, Roques P, Drancourt M. Use of a mobile cart influenza program for vaccination of hospital employees. Infect Control Hosp Epidemiol. 2004:25:918-22.

17. Lee HY, Fong YT. On-site influenza vaccination arrangements improved influenza vaccination rate of employees of a tertiary hospital in Singapore. Am J Infect Control. 2007;35:481-3.

18. Aloe C, Kulldorff M, Bloom BR. Geospatial analysis of nonmedical vaccine exemptions and pertussis outbreaks in the United States. Proceedings of the National Academy of Sciences. 2017;114(27):7101-5.

19. Kara EO, Campbell H, Ribeiro S, Fry NK, Litt D, Eletu S, Amirthalingam G. Survey of household contacts of infants with laboratory-confirmed pertussis infection during a national pertussis outbreak in England and Wales. Pediatr Infect Dis J. 2017;36:140-5.

20. Wendelboe AM, Njamkepo E, Bourillon A, Floret DD, Gaudelus J, Gerber M, Grimprel E, Greenberg D, Halperin S, Liese J, et al. Transmission of Bordetella pertussis to young infants. Pediatr Infect Dis J. 2007;26:293-9.

\section{Publisher's Note}

Springer Nature remains neutral with regard to jurisdictional claims in published maps and institutional affiliations.

Ready to submit your research? Choose BMC and benefit from:

- fast, convenient online submission

- thorough peer review by experienced researchers in your field

- rapid publication on acceptance

- support for research data, including large and complex data types

- gold Open Access which fosters wider collaboration and increased citations

- maximum visibility for your research: over $100 \mathrm{M}$ website views per year

At $\mathrm{BMC}$, research is always in progress.

Learn more biomedcentral.com/submissions 